\title{
Cystic echinococcosis: Late rupture and complication of a stable pulmonary cyst
}

\author{
J Fisher $M D^{1}$, Y Shargall $M D^{2,3}, S$ Krajden $M D^{4}, F$ Moid $M D^{5}$, V Hoffstein $M D^{3}$
}

\author{
J Fisher, Y Shargall, S Krajden, F Moid, V Hoffstein. Cystic \\ echinococcosis: Late rupture and complication of a stable pulmonary \\ cyst. Can Respir J 2011;18(5):258-260.
}

Cystic echinococcosis is observed worldwide. Traditional management includes an invasive surgical approach with adjunctive chemotherapy. It has been suggested that observation alone may be appropriate in asymptomatic individuals with stable cysts. A case involving a 38-year-old Peruvian man with an asymptomatic bronchogenic cyst (suspected to be due to echinococcus, but never definitely diagnosed) is presented. The cyst was first noted in 1998, and was followed for 10 years during which time he remained asymptomatic with minimal radiographic change. One year later, in 2009, he presented with acute rupture of the cyst causing empyema. The patient required thoracotomy, decortication and resection of the ruptured cyst. Final pathology showed Echinococcus organisms. The patient responded well to treatment with albendazole and praziquantel, and became completely asymptomatic within six months.

The present case demonstrates that echinococcal cysts may be at risk of spontaneous rupture, even after many years of clinical stability, thus supporting the case for resection of asymptomatic cysts suspected of being echinococcal at the time of diagnosis. In addition, the case illustrates that medical therapy with albendazole and praziquantel, in conjunction with surgical drainage, can be successful in the treatment of echinococcal empyema.

Key Words: Albendazole; Praziquantel; Pulmonary echinococcus

Cystic echinococcosis is observed worldwide. The majority of cases Cencountered in Canada occur among immigrants from endemic countries (1). Pulmonary involvement occurs in approximately $25 \%$ of cases. The liver is the most commonly affected organ, followed by the lungs (2). Although observation alone may be appropriate (3) for certain echinococcal cysts (generally hepatic), traditional management of hydatid cysts includes an invasive surgical approach with adjunctive chemotherapy. More recently, laparoscopic, percutaneous and parenchymal-sparing interventions have been introduced; however, the evidence to inform guidelines regarding the type of surgical procedure and medical management is limited.

\section{CASE PRESENTATION}

A 38-year-old man, a recent immigrant to Canada from Peru, was referred in 1998 due to an abnormal chest radiograph performed for immigration purposes, showing a right lower lobe opacity (Figure 1A). He was admitted to Canada but was advised to consult a physician. The patient was a lifelong nonsmoker, previously healthy, with no history of any pulmonary disease including chest trauma, shortness of breath, cough or constitutional symptoms. He was not taking any medications. His physical examination was normal. No previous chest radiographs were available for comparison.

A computed tomography (CT) scan of the patient's chest confirmed a rounded, low-attenuation mass with an enhancing rim, consistent with a bronchogenic cyst measuring $4 \mathrm{~cm} \times 3 \mathrm{~cm} \times 1.5 \mathrm{~cm}$ (Figure 1B). The possibility of cystic echinococcosis was raised. However, the patient was clinically asymptomatic and, thus, no medical or surgical intervention other than clinical and radiographic follow-up was deemed necessary. Between 1998 and 2000, he remained clinically asymptomatic.

\section{L'échinococcose kystique : la rupture tardive et la complication d'un kyste pulmonaire stable}

L'échinococcose kystique s'observe partout dans le monde. Une approche chirurgicale effractive accompagnée d'une chimiothérapie d'appoint en est la prise en charge classique. Il a été postulé que l'observation seule pourrait suffire chez les personnes asymptomatiques dont le kyste est stable. Le cas d'un homme péruvien de 38 ans ayant un kyste bronchogénique asymptomatique (qu'on présumait être une échinococcose, mais qui n'avait jamais été officiellement diagnostiqué) est présenté. Le kyste a été remarqué pour la première fois en 1998 et a été suivi pendant dix ans, au cours desquels il est demeuré asymptomatique et a très peu évolué à la radiographie. Un an plus, tard, en 2009, l'homme a consulté en raison d'une rupture aiguë du kyste, responsable d'un empyème, et a dû subir une thoracotomie, une décortication et une résection du kyste rompu. La pathologie définitive a révélé des organismes d'Echinococcus. Le patient a bien répondu au traitement à l'albendazole et au praziquantel et était devenu complètement asymptomatique au bout de six mois. Le présent cas démontre le risque que l'échinococcose kystique se rompe spontanément, même après de longues années de stabilité clinique, ce qui appuie la résection des kystes asymptomatiques qu'on croit de nature échinococcique, et ce, dès leur diagnostic. De plus, le cas démontre qu'une pharmacothérapie à l'albendazole et au praziquantel, conjointement avec un drainage chirurgical, peut traiter avec succès l'empyème de natureéchinococcique.

CT measurements of the cyst in 2000 showed some enlargement - it now measured at $5 \mathrm{~cm} \times 4 \mathrm{~cm} \times 3 \mathrm{~cm}$. The patient was followed at least annually until 2002. He continued to be completely asymptomatic and, in fact, did not attend his follow-up appointments from 2003 onward.

The patient returned in 2007 only at the insistence of his family physician. He stated that in the intervening five years, he had remained completely asymptomatic, as he was during his current visit. A repeat CT scan of the thorax in 2007 (Figure 1C) showed no change in the size of the cyst, now measuring $5 \mathrm{~cm} \times 4 \mathrm{~cm} \times 3.5 \mathrm{~cm}$. He was seen once again in 2008 and was asymptomatic, with chest radiography (Figure 1D) showing no change from previous imaging. $\mathrm{He}$ desired to discontinue regular follow-up.

He returned at his own request one year later, in August 2009, with a one-month history of shortness of breath, cough, right-sided pleuritic chest pain, fever, chills, night sweats and a $4.5 \mathrm{~kg}$ weight loss. He had already been prescribed two courses of antibiotics (cefuroxime and clarithromycin), with no significant improvement.

A chest examination revealed dullness to percussion and absent breath sounds over the right lower lung field. His white blood cell count was $9.13 \times 10^{9} / \mathrm{L}$ with $25 \%$ eosinophils. The chest radiograph showed right pleural effusion. A CT scan of the thorax confirmed that the previously well-circumscribed bronchogenic cyst had ruptured (Figures 2A and B). Analysis of the pleural fluid revealed that it was an exudate with a $\mathrm{pH}$ of 7.48 and cell count of $120 \times 10^{6} / \mathrm{L}(86 \%$ neutrophils and 2\% eosinophils). Pleural fluid culture was negative.

Despite initial therapy with chest tube drainage and broad spectrum intravenous antimicrobial therapy, the patient continued to complain of cough, chest pain, shortness of breath and generalized fatigue. Pleural

${ }^{1}$ Department of Medicine, University of Manitoba, Winnipeg, Manitoba; ${ }^{2}$ Department of Surgery, St Joseph's Hospital; ${ }^{3}$ Department of Medicine,

St Michael's Hospital, University of Toronto; ${ }^{4}$ Department of Medicine; ${ }^{5}$ Department of Pathology, St Joseph's Hospital, Toronto, Ontario

Correspondence: Dr Victor Hoffstein, Department of Medicine, St Michael's Hospital, University of Toronto, 30 Bond Street, Toronto,

Ontario M5B 1W8. Telephone 416-360-4000, fax 416-864-5649, e-mail victor.hoffstein@utoronto.ca 

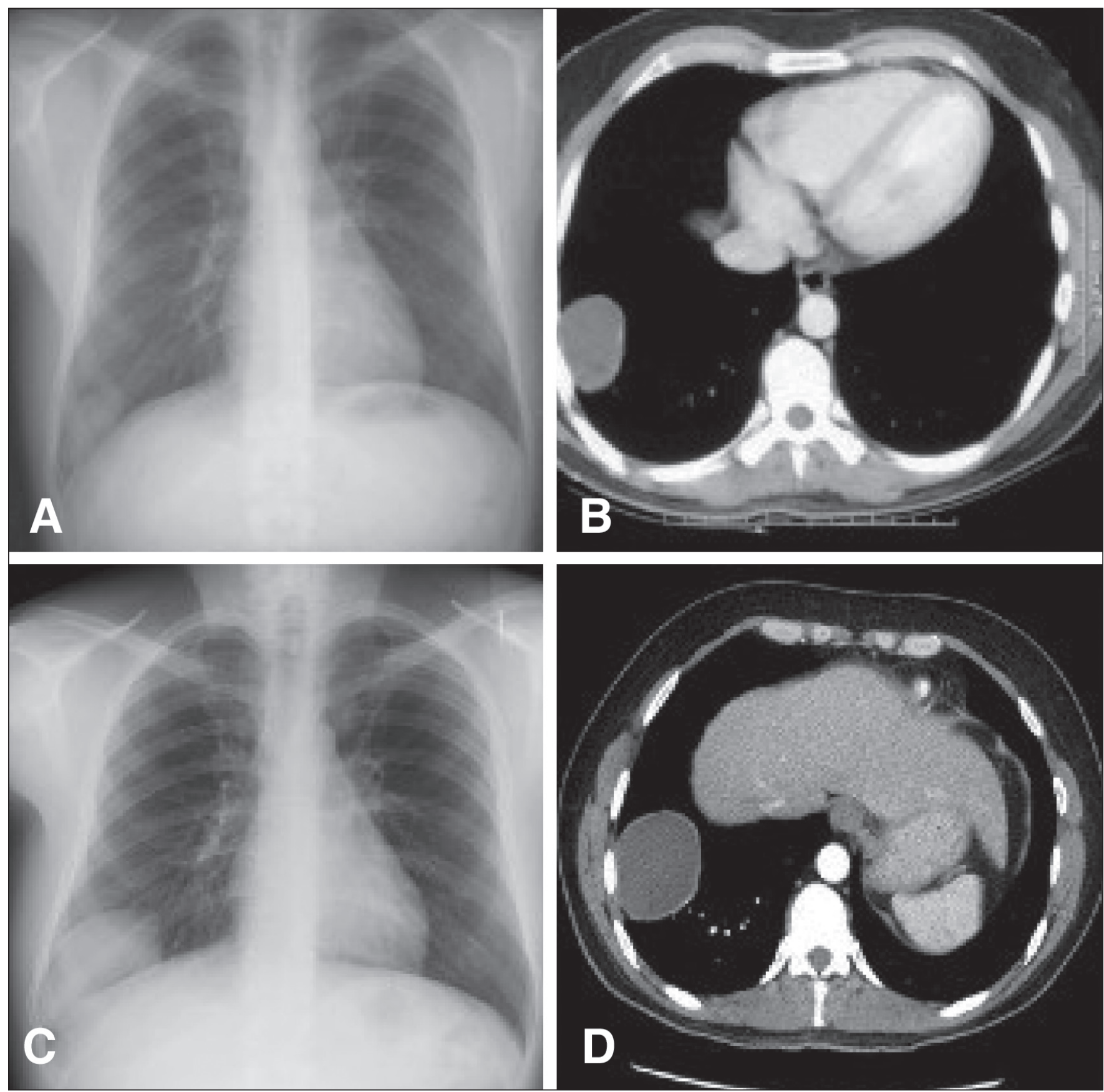

Figure 1) A Chest radiograph on initial presentation in 1998. B Computed tomography scan of the chest on initial presentation in 1998. C Chest radiograph after 10 years of observation in 2008. D Computed tomography scan of the chest after nine years of observation in 2007

effusion was decreased, but was not completely eliminated despite several attempts to reposition and flush the chest tube. Surgical treatment was recommended. Five days after his admission to the respirology service, the patient underwent a right thoracotomy with decortication and resection of the ruptured cyst. Final pathology showed Echinococcus organisms (Figure 3). Medical therapy with albendazole and praziquantel was initiated. The patient tolerated these medications well throughout the three-month course. He improved rapidly and, when seen at follow-up three months and one year after discontinuation of medical therapy, he was asymptomatic with a virtually normal chest x-ray (Figure 4).

\section{DISCUSSION}

The present case illustrates that even long-standing and asymptomatic echinococcal cysts may rupture, and require combined surgical and medical management.

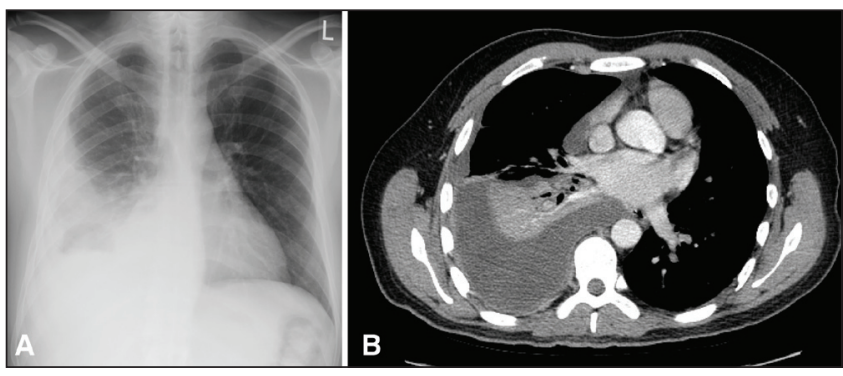

Figure 2) Chest radiograph (A) and computed tomography scan (B) of the chest on presentation in 2009 

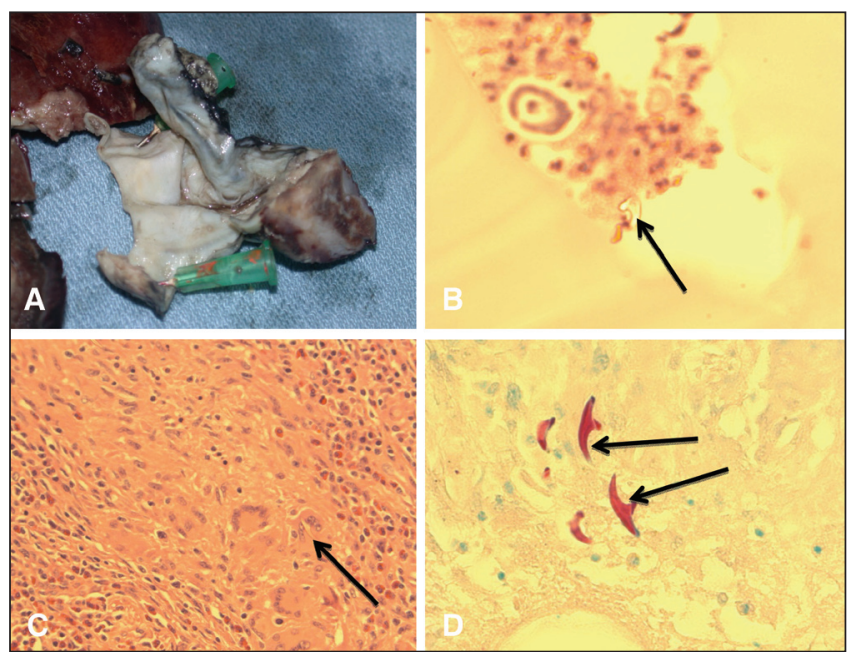

Figure 3) A Gross picture of cyst wall. B Hematoxylin and eosin stain showing acellular and germinal layer of the cyst wall with echinococcal hooklet (arrow). C High-power view of hematoxylin and eosin stain of lung tissue giant cell containing echinococcal hooklet (arrow). D Ziehl-Neelsen stain highlighting the hooklets (arrows)

When feasible, surgery $(4,5)$ has traditionally been the treatment of choice for pulmonary hydatid disease. While percutaneous methods such as puncture, aspiration, injection and reaspiration (PAIR) are used with increasing frequency in the management of hepatic echinococcal disease, their use in pulmonary hydatid disease has been more limited. Gabal et al (6), described the use of a modified PAIR technique on five pulmonary hydatid cysts. Complications were limited to one pneumothorax. All cysts decreased in size, but none resolved completely. Recently, centres experienced in the management of cystic echinococcosis have suggested that observation alone of certain hydatid disease is sufficient (3), although this recommendation is probably more applicable to hepatic than pulmonary cysts, which demonstrate low rates of disease progression and complications (7). However, this 'watch and wait' approach has not been formally evaluated. Aribas et al (8) found high rates of morbidity $(16.3 \%)$ and mortality $(2.3 \%)$ in patients who presented with complications of pulmonary hydatid disease and subsequently suggested early surgical intervention.

The most recent update on pulmonary cystic echinococcosis (5) confirmed the previous recommendation (identifying surgery as the main therapeutic approach) and points out that the optimum timing of surgery in asymptomatic patients is unknown, that most patients are operated on after many years of infection and that nearly $50 \%$ present with complications - presumably, rupture and infection.

Patients who cannot undergo surgery for various reasons are treated medically. The most extensively studied drug for medical treatment of echinococcal cysts is albendazole. It is recommended as first-line chemotherapy in the treatment of cystic echinococcal disease (9). There is limited evidence to suggest that, in the setting of cyst rupture, the use of combination therapy with albendazole and praziquantel may reduce the risk of postoperative echinococcal recurrence (10).

Our case demonstrates that medical therapy with albendazole and praziquantel, in conjunction with surgical drainage, is successful in the treatment of echinococcal empyema. Furthermore, although Canada

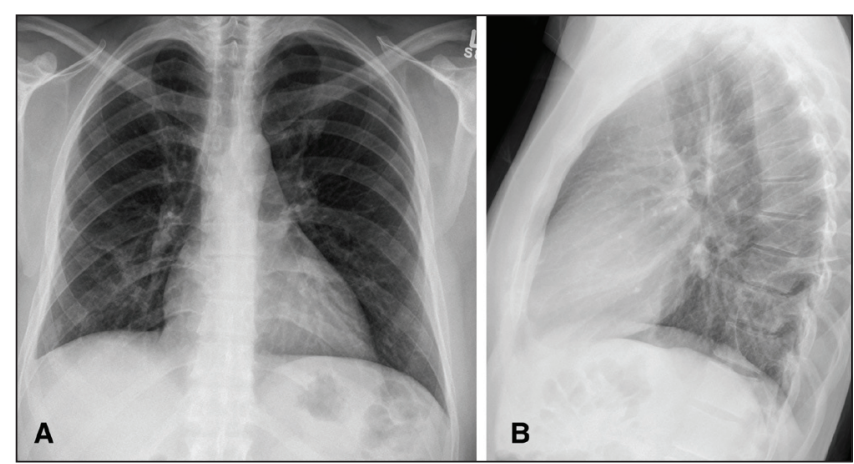

Figure 4) Chest radiographs (A,B) one year after surgery showing only minor scarring in the right lower lobe

is not a country in which echinococcal disease is common, it clearly needs to be suspected in all immigrants arriving from endemic areas, whose chest radiograph shows bronchogenic cysts suspected of being due to Echinococcus organisms.

Finally, although the natural inclination in a stable asymptomatic patient with benign pulmonary lesion is to observe - rather than operate - this may not be the best approach in the case of echinococcal cysts, which may rupture spontaneously even after many years of clinical stability. Early surgery may be the best way to proceed to prevent eventual rupture of the cyst. Although there is no consensus as to the best surgical approach, current opinion (5) is that excision of the cyst using the parenchymal sparing technique (11) is the preferred approach. The surgery is safe, without any perioperative mortality, and with less than $9 \%$ morbidity, the most common being atelectasis, pleural effusion, prolonged air leak, hemoptysis and wound infection.

\section{REFERENCES}

1. Junghanss T, Menezes da Silva A, Horton J, Chiodini PL, Brunetti E. Clinical management of cystic echinococcosis: State of the art, problems and perspectives. Am J Trop Med Hyg 2008;79:301-11.

2. Kammerer WS, Schantz PM. Echinococcal disease. Infect Dis Clin North Am 1993;7:605-18.

3. Brunetti E, Junghanss T. Update on cystic hydatid disease. Curr Opin Infect Dis 2009;22:497-502.

4. Morar R, Feldman C. Pulmonary echinococcosis. Eur Respir J 2003;21:1069-77.

5. Santivanez S, Garcia HH. Pulmonary cystic echinococcosis. Curr Opinion Pulmon Med 2010;16:257-61

6. Gabal AM, Khawaja FI, Mohammad GA. Modified PAIR technique for percutaneous treatment of high-risk hydatid cysts. Cardiovasc Intervent Radiol 2005;28:200-8.

7. Frider B, Larrieu E, Odriozola M. Long-term outcome of asymptomatic liver hydatidosis. J Hepatol 1999;30:228-31.

8. Aribas OK, Kanat F, Gormus N, Turk E. Pleural complications of hydatid disease. J Thorac Cardiovasc Surg 2002;123:492-7.

9. Horton J. Albendazole in the treatment of human cystic echinococcosis. Acta Tropica 1997;64:79-93.

10. Bygott JM, Chiodini PL. Praziquantel: Neglected drug? Ineffective treatment? Or therapeutic choice in cystic hydatid disease? Acta Tropica 2009;111:95-101.

11. Dakak M, Gaylak H, Gozubuyuk A, et al. Parenchyma saving surgical treatment of giant pulmonary hydatid cysts. Thorac Cardiov Surg 2009:57;165-8. 


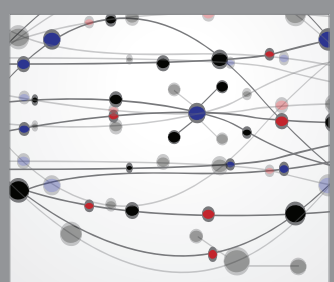

The Scientific World Journal
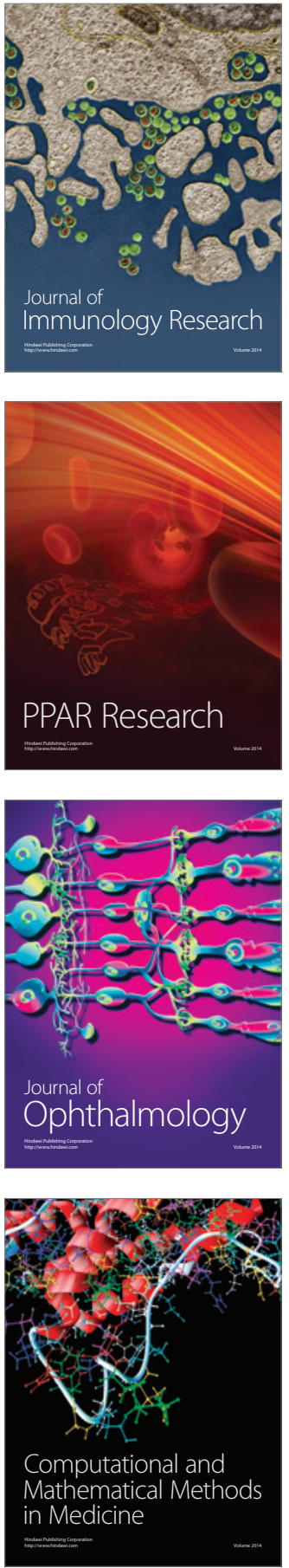

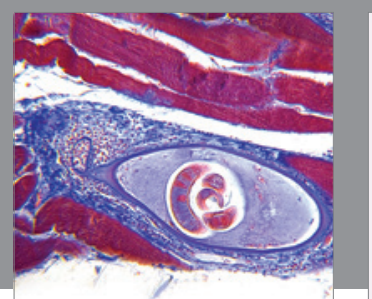

Gastroenterology Research and Practice

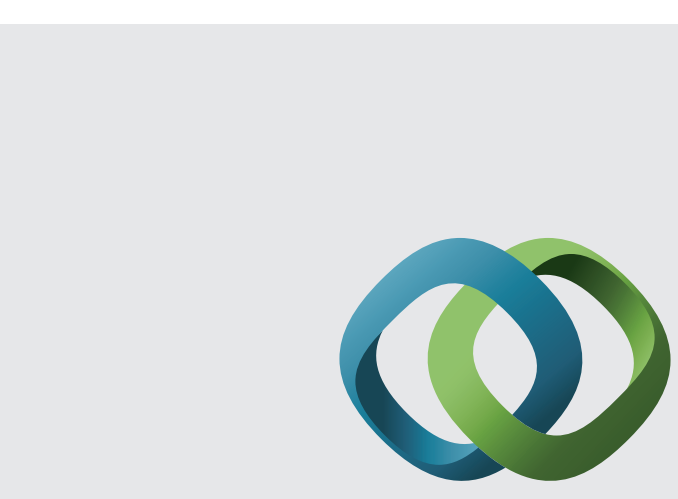

\section{Hindawi}

Submit your manuscripts at

http://www.hindawi.com
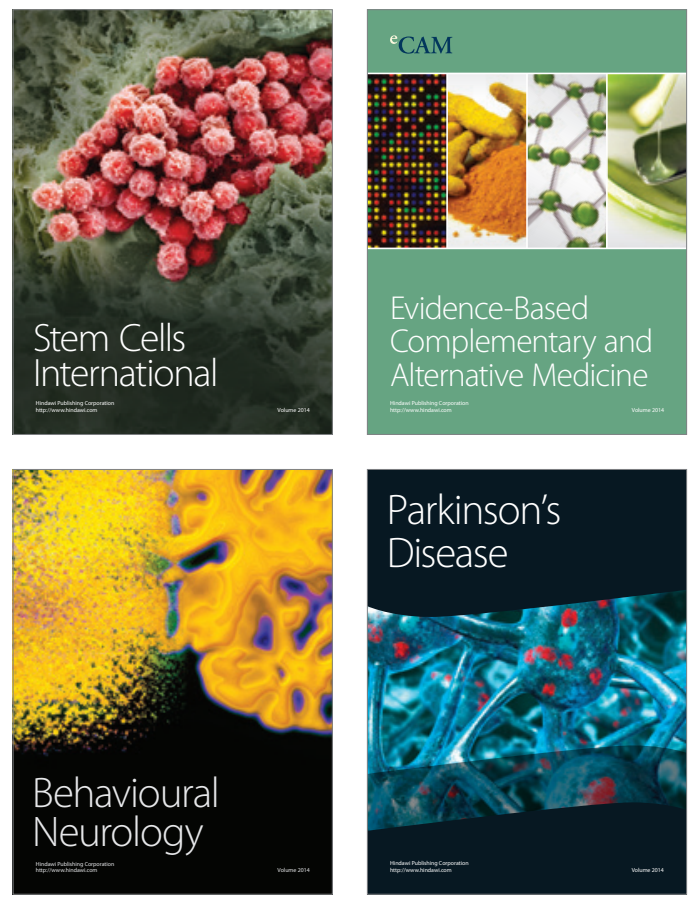
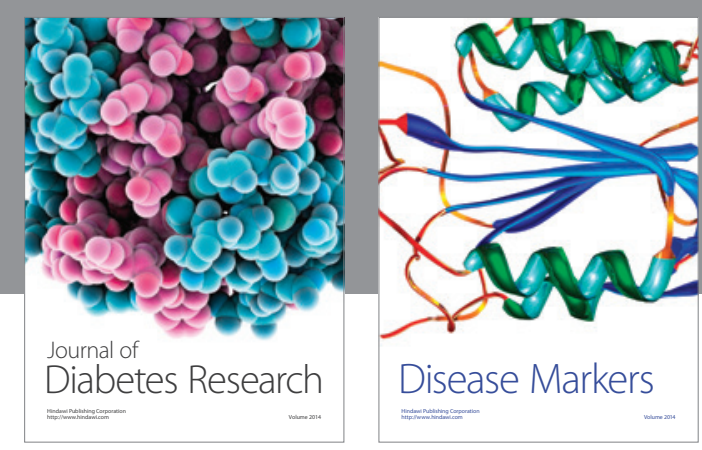

Disease Markers
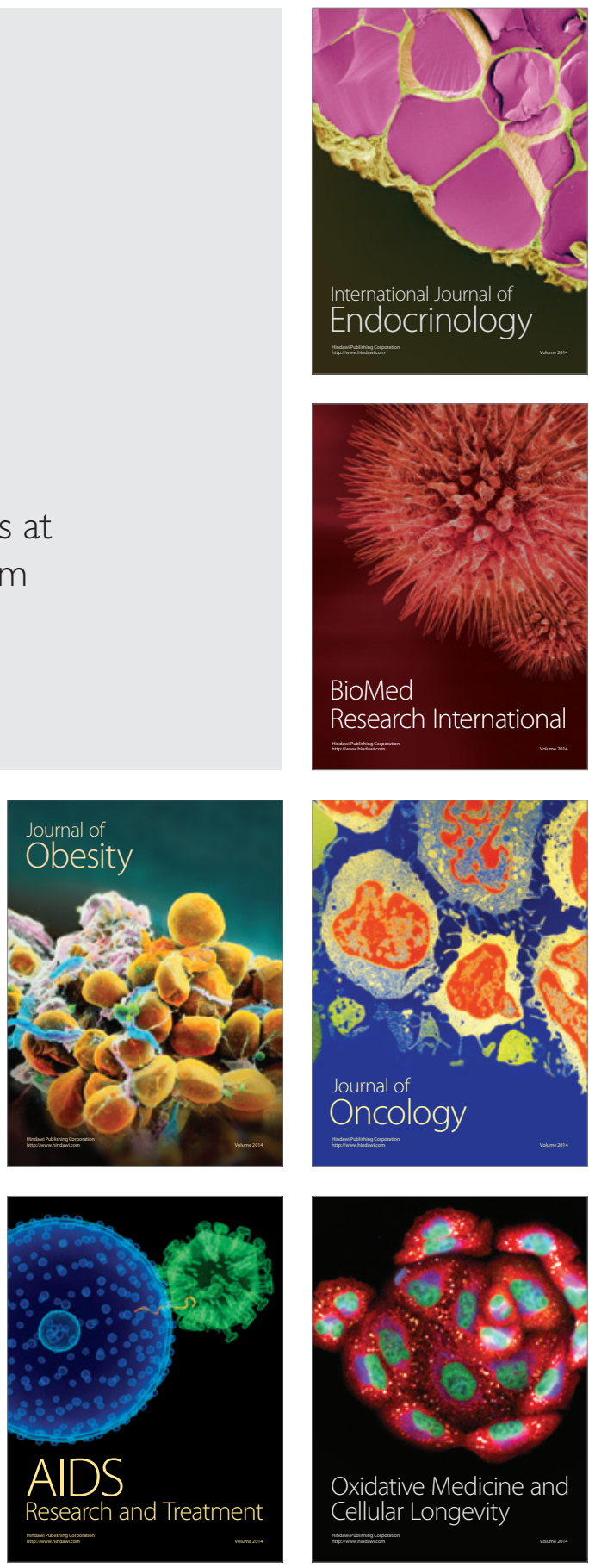